\title{
De nuevo sobre la organización de la justicia en el Levante andalusí en el periodo almorávide. El caso de Alcira*
}

\author{
Once again about the Andalusi Levant's judicial Administration in the \\ Almoravid Period. The case of Alcira
}

\author{
Rachid EL HouR \\ Universidad de Salamanca \\ raelhour@usal.es
}

Recibido: 26 de enero de 2015

Aprobado: 7 de mayo de 2015

\begin{abstract}
RESUMEN
En una ocasión anterior, realicé un estudio amplio sobre el cadiazgo de toda la zona del Levante y he llegado a varios conclusiones relativas al funcionamiento de la justicia en esta zona, y cómo controlaba el poder local levantino el cadiazgo en las diversas localidades levantina. Vamos a ver cómo afectó la política judicial almorávide aplicada en toda la zona del Levante al cadiazgo de Alcira. Para ello, esta contribución intentará abordar dos aspectos primordiales. Por una parte, hará un breve análisis de los datos históricos que ofrecen las fuentes árabes para ver cómo la presentan, pero sobre todo para estudiar la evolución política de la localidad y su papel en los posibles cambios judiciales y administrativos que hubiera sufrido durante el periodo que se extiende desde finales de la época de taifas hasta finales del periodo almorávide en al-Ándalus. Por otra parte, se analizará la composición del cadiazgo de la localidad, con el objetivo de estudiar los posibles cambios producidos en la época almorávide.

Palabras clave: cadiazgo, al-Ándalus, Levante, Alcira, taifas, almorávides.
\end{abstract}

\begin{abstract}
On a previous occasion I studied the qā sions on the functioning of Justice in this area and how the local power controlled the judicial administration in the different towns. This time, we are going to assay how the Almoravid judicial politics that were applied in the Levant affected Alcira's qădiship. For this reason, this contribution will address two main aspects. On the one hand it will make a brief analysis of the historical information offered by the Arabic sources in order to see how it is presented and, above all, to study the political evolution of the city and its role in the possible judicial and administrative changes that had occurred during the period extending from the end of the Taifas until the end of the Almoravid periods. On the other hand, it will analyze the composition of the judicial administration of Alcira with the aim of studying probable changes in the Almoravid period.
\end{abstract}

Keywords: $q \bar{a} d \bar{\imath} \bar{s} h i p$, al-Andalus, Levant, Alcira. Taifas, Almoravids.

* Este estudio se enmarca dentro de los resultados del proyecto de investigación $\mathrm{I}+\mathrm{D}+\mathrm{i}$ "Hagiografía y literatura hagiográfica en al-Andalus y el Magreb desde la época medieval hasta la actualidad: cuestiones de identidad cultural y religiosa" (Hagiomag) (financiado por el Ministerio de Economía y Competitividad, No Referencia FFI2011-24049). Agradezco a Rafael Mayor la revisión de este estudio. 
Hace unos años, publiqué un estudio sobre lo organización judicial almorávide en al-Ándalus. El libro aborda diversos temas pero resalta especialmente las líneas generales del funcionamiento de la institución de la justicia en las urbes más importantes, como Córdoba, Sevilla Granada, Almería, Málaga Valencia y Murcia. También analicé algunas características del funcionamiento de la justicia en diversas localidades andalusíes de menor importancia, las denominados "marginales o periféricas", en este mismo periodo en diversos estudios ${ }^{2}$.

Sin embargo, en el capítulo dedicado al cadiazgo de la zona del Levante 3 , y por falta de tiempo en su día no pude llevar a cabo un estudio pormenorizado de algunas de las localidades estudiadas, como es el caso de Alcira, o ŷazirat šuqr, tal como se conoce en las fuentes árabes. He creído necesario aprovechar esta nueva ocasión para realizar este estudio pendiente, un análisis más completo de la organización de la administración judicial que refleje realmente la importancia histórica de la que gozó Alcira en la historia de al-Ándalus, especialmente en el periodo almorávide. Mi objetivo, entre otros, es poner de manifiesto algunas características judiciales propias de las ciudades de frontera ${ }^{4}$.

${ }^{1}$ Véase EL HOUR, Rachid, La administración judicial de los almorávides en al-Ándalus. Élites, negociaciones y enfrentamientos, Helsinki: Humaniora, 2006.

${ }^{2}$ Véase en particular EL HOUR, Rachid,“Algeciras, ciudad "magrebí” en al-Ándalus: una reflexión acerca de su administración de justicia", Quaderni Di Studi Arabi (2006),69-79; "Sobre el cadiazgo de al-Ándalus "marginal" en el período almorávide (Arcos de la Frontera, Morón de la Frontera, Carmona y Ronda)", Hesperia, Culturas del Mediterráneo 17 (2013), 171-193; "De nuevo sobre el cadiazgo de al-Ándalus almorávide: reflexiones acerca del cadiazgo de Almuñécar", Studia Orientalia, vol. 114 (2013), 167-178; "Reflexiones acerca del desarrollo de la justicia en Alcalá la Real en el período almorávide", en Islam y Cristiandad. Siglos XI-XVI. Los Banū Sa ìd. Actas del Congreso Internacional-Homenaje a María Jesús Viguera Molins 14-15 noviembre 2008, F. TORO CEBALLOS Y J. RODRÍGUEZ MOLINA (coords.), Jaén: Diputación Provincial de Jaén, 2009, 249-256; "De nuevo sobre el cadiazgo periférico andalusí en época almorávide. Reflexiones acerca de la organización judicial de Guadix", Anaquel de Estudios Árabes e Islámicos, vol. 23 (2012), 45-54; "De nuevo sobre el cadiazgo de la justicia en al-Andalus periférico en época almorávide: el caso de Quesada", Estudios de Frontera. 9. Economía, derecho y sociedades en la Frontera. Homenaje a Emilio Molina López, F. TORO CEBALLOS, J. RODRÍGUEZ MOLINA (coords.), Jaén: Diputación Provincial de Jaén: Diputación Provincial de Jaén, 2014, 311-316.

${ }^{3}$ Véase en particular EL HOUR, Rachid, "El Levante de al-Ándalus en época almorávide: jueces y élites locales", Al-Ándalus-Magreb X (2003), 53-89.

${ }^{4}$ No es lugar para analizar el concepto de "Frontera", ya que es un tema un poco complejo y necesita un espacio mucho más amplio que unas simples líneas. Me limitaré a recomendar algunos estudios que pueden ayudar a esclarecer este asunto. Véase en particular el excelente estudio de BAZZANA, André, "El concepto de frontera en el Mediterráneo occidental en la edad media", Actas de Congreso la frontera oriental Nazari como sujeto histórico (siglos XIII-XVI), Lorca-Vera 22-24 noviembre 1994, Almería, 1997, 25-46, espec. 32-36. También se puede consultar la obra de MANZANO MORENO, Eduardo, La frontera de al-Andalus en época de los omeya, Madrid: CSIC, 1991. Véanse también los trabajos que guardan relación con el tema que nos preocupa en este estudio: la ciudad de Jaén a su vez tuvo algunas características judiciales que respondían a su condición de ciudad frontera: EL HOUR, Rachid,"El cadiazgo de Jaén en la época almorávide: una propuesta de interpretación" en Cadies y cadiazgo en al-Andalus y el Magreb medieval (E.O.B.A.,vol. XVIII), R. EL HOUR (ed. 
Como se ha comentado ante, he realizado un estudio amplio sobre el cadiazgo de toda la zona del Levante y he llegado a varias conclusiones relativas al funcionamiento de la justicia en esta zona, y cómo las familias locales controlaban el cadiazgo en las diversas localidades levantinas. Vamos a ver cómo afectó la política judicial almorávide aplicada en toda la zona del Levante al cadiazgo de Alcira. Para ello, esta contribución intentará abordar dos aspectos primordiales. Por una parte hará un breve recurrido entre las fuentes árabes para ver cómo la presentan, pero sobre todo para estudiar la evolución política de la localidad y su papel en los posibles cambios judiciales y administrativos que hubiera sufrido durante el periodo que se extiende desde finales de la época de taifas hasta finales del periodo almorávide en al-Ándalus. Por otra parte, se analizará la composición del cadiazgo de la localidad, con el objetivo de estudiar los posibles cambios producidos en la época almorávide.

\section{ALGUNOS DATOS HISTÓRICOS}

La historia de Alcira ha de ser tratada dentro del marco general de la historia del Levante, y particularmente en la época almorávide, por la nueva organización administrativa que aplicaron los almorávides en esta zona de al-Ándalus. Nos permitimos ofrecer algunas ideas acerca de su historia a lo largo del período que nos ocupa.

No disponemos de muchos datos sobre la historia de Alciras. Algunos autores árabes, como al-Idrīsī, destacan el papel de ŷazirat Šuqr en el Levante y dicen que Alcira formaba parte del reino de Valencia' ${ }^{6}$. Por su parte, Ibn 'Idāāī nos informa de que Alcira era una de las provincias o dependencias del reino de `Abd al-`Azīz b.

Científica) y R. MAYOR (ed. Técnica), Madrid: CSIC, 2012, 169-185. Véase también MARTOS QUESADA, Juan y BUENOS SÁNCHEZ, María (eds.), Frontera en discusión. La península Ibérica en el siglo XII, Madrid: Almudayna, 2012.

${ }^{5}$ Véase, CHABAS, Roque, RIBERA y TARAGO, PONS BOIGUES, Francisco, "Textos sobre Alcira y Játiva árabes", Sharq Al-Andalus., I (1984), 185-197; Ŷ̀ARRĀR, Șālāḥ, "Ŷazīrat Šuqr alandalusiyya, al-zamān wa-l-makān fi l-adab al-andalusī", Maŷallat Maŷma al-Luga al- 'Arabiyya alUrdunī, 34 (1988), 151-195; CASTRILLO MÁRQUEZ, Rafaela, "Alzira. Apuntes para su historia medieval (siglos XI-XIII)", Sharq al-Andalus, VIII (1991), 255-268

${ }^{6}$ Cf. Ibn Sa`īd, al-Mugrib fi hulà al-Magrib, ed. Š. ḌAYF, El Cairo: Dār al-Ma’ārif, 1953, t. II, 295. Ibn Sa'îd la sitúa en el reino de Valencia bajo el nombre de Kitāb al-Rawḍa al-narŷisisiyya fi hulà al-mamlaka al-balansiyya. También al-Himyarī habla de Alcira y destaca las características agrícolas, urbanas y culturales de esta ciudad. Dice: "Elle possède un sol fertil, avec de nombreux arbres fruitiers et des ruisseaux. Elle est habitée par des gens de qualité". Véase La Péninsule Ibérique au Moyen-Âge d'après le kitab ar-rawd al-mi tar fi jabar al-aqtar, ed. y trad. E. Lévi-Provençal, Leiden, E.J. Brill, 1938, texto, p. 102-103, trad., p. 126; Al-IDRĪSİ, Description de l'Afrique et de l'Espagne par Edrissi. Texte arabe avec une traduction par DOZY et M.J. de GOEJE, Leinde, 1866, texto, p. 193, trad., p. 233. Véase también, IBN ḨAYYĀN, Al-Muqtabis, t. V, ed. Pedro CHALMETA y Federico CORRIENTE, Mạ̣mūd `Alī MAKKĪ, Madrid: Instituto Hispano-Árabe de Cultura, 1979, 518.

${ }^{7}$ Al-Bayān al-mugrib, ed. Ambrosio HUICI MIRANDA, Muhammad Ben TAWIT y Muhammad. AL-KATTĀNĪ, Tetuán, 1963. t. III,139. 
'Āmir, al-Manșūr, de Valencia ${ }^{8}$, que permaneció en ella hasta su muerte en 452/1060-1061'. Le sucedió su hijo `Abd al-Malik, que perdió la ciudad más importante del reino de su padre, es decir, Valencia, a favor de al-Ma'mūn b. Dī l-Nūn de Toledo en 457/1064-1065 ${ }^{10}$. El rey de Toledo nombró a Abū `Abd Allāh b. `Abd al-'Azīz, conocido por Rawbaš, gobernador de la ciudad. Pensamos que la caída de Valencia en manos del rey de Toledo implicaba probablemente la caída de sus dependencias, ya que tras el regreso de al-Ma'mūn a Toledo se levantó en Valencia Abū Bakr b. `Abd al- 'Azīz b. al-Manșūr b. Abī 'Āmir y se hizo con el poder de la ciudad y con el de Alcira ${ }^{11}$ hasta principios de 478/1085-1086 ${ }^{12}$. Le sucedió su hijo Abū 'Amr 'Uțmān b. Abī Bakr Muḥammad b. 'Abd al- 'Azīz, que permaneció en ella hasta que al-Qādir b. Di 1-Nūn de Toledo la entregó a Alfonso VI, rey de Castilla y León, a cambió de ayudarle para apoderarse de Valencia. En 478/1085-1086 $6^{13}$ al-Qādir entró en Valencia y Alcira. De nuevo otro cambio se produjo en Valencia. El cadí de Valencia, Abū Aḥmad Ŷa far b. Yạ̣hāf, tomó el poder de la ciudad y se proclamó $r a^{\prime} \bar{\imath} s$ de Valencia ${ }^{14}$. No cabe duda de que estos acontecimientos afectaron a la evolución de la administración judicial de Alcira, ya que era dependencia de Valencia.

El proyecto expansionista almorávide en al-Ándalus llegó al Levante alrededor de 484/1091, ya que a partir de esta fecha la mayor parte del Levante había caído en manos de los almorávides. Pero este proyecto fue detenido por la presencia del Cid en esta zona y su conquista de una parte importante de las ciudades, en particular Valencia.

Tenemos constancia de que Alcira estaba ya bajo el poder almorávide ${ }^{15}$ cuando el Cid tomó Valencia, ya que entraron en ella en el verano de $1092^{16}$. Y probablemente Alcira estaba bajo control del gobernador almorávide Ibn 'Ā'iša, que residía

\footnotetext{
${ }^{8}$ Véase la administración judicial de Valencia en la obra La organización judicial almorávide en al-Andalus, capítulo VI.

${ }^{9}$ IBN BASSĀM, al-Dַajīra fì mahāsin ahl al-ŷazīra, ed, Iḥsān `ABBĀS, El Cairo, 1979, vol. Vol. $\mathrm{III} / 1,517$.

${ }^{10} \mathrm{Ibn} ` \mathrm{ID} \mathrm{A} \mathrm{R} \overline{\mathrm{I}}$, al-Bayān al-mugrib, t. III, p. 303.

${ }^{11}$ IBN `ABD AL-MALIK, al-Dַayl wa-l-takmila, ed. Muhammad BENŠARĪFA, Beirut, II, p. 591.

${ }^{12}$ Ibn `IDĀRĪ, al-Bayān al-mugrib, t. III, p. 304.

${ }^{13} \mathrm{Ibn}$ 'IDĀR̄i, al-Bayān al-mugrib, t. III, p. 304.

${ }^{14}$ Véase la evolución de los hechos en la administración judicial de Valencia. Sobre la familia de los Banū Ŷaḥāaf véase la entrada de NAVARRO OLTRA, Vicente Carlos en Biblioteca de al-

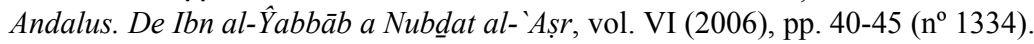

${ }^{15}$ Cf. IBN AL-KARDABŪS, Ta'rīj al-Andalus li-Ibn al-Kardabūs, ed. Aḥmad Mujtār alABBĀDĪ, Madrid, 1971,14; Cf. VIGUERA MOLÍNS, María Jesús, Los reinos de taifas y las invasiones magrebies, Madrid: Mapfre, 1992, 108-109 (Existe una segunda edición de esta obra: Los reinos de taifas, Madrid, RBA, Biblioteca Historia de España, $2^{\mathrm{a}}$ ed., 2007. La obra ha sido traducido recientemente por Mustafa AMMADI y Muhammad SALHI, a la lengua árabe con el título: Mulūk al-țawâif, Rabat: Edition \& Impressions Bouregreg, 2010); HUICI MIRANDA, Ambrosio, Historia musulmana de Valencia y su región, Valencia, 1970, t. II, 62-64 y 68.

${ }^{16}$ Cf. VIGUERA MOLINS, María Jesús, Los reinos de taifas, p. 81.
} 
en Murcia. Por consiguiente, al menos en este momento la administración judicial se libró, en cierto modo, de los acontecimientos que ocurrían en Valencia, ocupada por el Cid.

Pensamos que la presencia del Cid en Valencia fue un gran obstáculo a las reformas que introdujeron los almorávides en el Levante, y que la política de éstos no se aclaró hasta que la ciudad fuese abandonada en 495/1102 por los cristianos. Alcira permaneció bajo control almorávide pese a la gran ofensiva que efectuó Alfonso I, rey de Aragón, en 519/1125 contra todo el Levante ${ }^{17}$. Este dato nos lleva a deducir que la administración judicial de Alcira no se vio afectada por los acontecimientos sucedidos tras la caída de ésta en manos de los almorávides.

\section{CADIAZGO DE ALCIRA}

Creo que hemos de situar el cadiazgo de Alcira dentro del marco general de la política judicial aplicada por los almorávides en toda la zona del Levante. A pesar de que esta política haya sido ya estudiada en otra ocasión, creo que es oportuno y necesario recordar que la organización de la administración de justicia almorávide en Levante obedecía, entre otros factores, a razones político-militares, por ser zona limítrofe con los territorios enemigos. Dentro del marco general de la organización jurídica que introdujeron los almorávides en el Levante, la administración judicial, con la excepción de las Islas Baleares y Almería ${ }^{18}$, fue centralizada en las dos ciudades más importantes de esta zona: Murcia y Valencia. A pesar de que el representante del poder político-militar gobernaba en todo el Levante, la administración judicial se caracterizó, en cierta medida, por unos mecanismos que plasmaban características internas de cada una de las dos ciudades. En este sentido, hemos de tener presente que la mayoría de los cadíes de Murcia, por ejemplo, no sólo eran nombrados por el gobierno central ${ }^{19}$, como sucedió con Abū Bakr b. Aswad al-Gassānīīn, Abū `Alī al-Ṣadafî̀ ${ }^{21}$, Abū Umayya

\footnotetext{
${ }^{17}$ Véase CASTRILLO MÁRQUEZ, Rafaela, op.cit., p. 257.

${ }^{18}$ No he incluido estas dos administraciones porque no se consideraban zonas levantinas desde el punto de vista de la organización jurídica almorávide. Cada una de ellas gozaba de su respectiva administración de justicia y de su propia organización administrativa. Véase el cadiazgo de Almería en el periodo almorávide: "Almería almorávide: sede de una oposición política y de un importante poder judicial”, Revista del Instituto Egipcio de Estudios Islámicos en Madrid, XXXII, 99-118.

${ }^{19} \mathrm{La}$ intervención del gobierno central en el nombramiento de los cadíes de Murcia no era algo característico del cadiazgo de esta ciudad, sino que refleja en cierto modo la importancia de su cadiazgo, como podrían ser los casos de Valencia o Córdoba. Véase los estudios dedicados a estas dos ciudades en EL HOUR, Rachid, La administración judicial almorávides almorávide en al-Andalus, capítulos I y VI.

${ }^{20}$ IBN BAŠKUWWĀL, al-Şila, ed. 'I. al- 'ATṬT̄AR, El Cairo, no 1286; Al-ḌABBĪ, Bugyat almultamis, ed. I. Al-ABYĀRĪ, Beirut, 1989, nº 49. Véase también la entrada de LIROLA, Jorge en Biblioteca de al-Andalus. De Ibn Ac̣hà a Ibn Bušrà, vol. II (2009), pp. $402-404$ (nº 330).

${ }^{21}$ IBD BAŠKUWĀL, al-Şila, El Cairo, no 330; IBN FARḤÛN, al-Dībāŷy al-mudhab, ed. El Cairo, 1972, I, 330-332; Al-ḌABBĪ, Bugyat al-multamis, $\mathrm{n}^{\circ}$ 657; 'IYĀḌ, al-Gunya, ed. Muhammad ŶĀRRĀR, Beirut, 1982, 129-138; 'IYĀḌ, Tartīb al-madārik, ed. Varios editores, Rabat, 1983, vol. VIII, 193-194; IBN `AṬIYYA, Fihris, ed. Muḥmmad Al-ZĀHĪ y Muhmmad ABŪ L-AŶFĀN, Beirut, 1980, 74-76; MAJLŪF, Muhammad, Šaŷarat al-nūr, El Cairo, 1950-1952, no 128; AL-MAQQARĪ,
} 
Ibrāhīm Muḥammad b. Mintāal ${ }^{22}$, etc., sino que a veces el propio gobernador del Levante intervenía en el nombramiento de estos cadíes, como sucedió en el caso concreto de 'Āšir b. Muḥammad b. `Āšir b. Jalaf b. Muraŷŷā b. Hakam al-Anșāẫ $\overline{1}^{23}$, que fue nombrado por Abū Zakariyyā' b. Gāniya. Esta política y sus características son dos aspectos que han sido ilustrados en el estudio de la relación de los jueces de cada localidad levantina ${ }^{24}$, aunque sólo quería poner de manifiesto que la zona del levante ocupó un gran interés político-judicial para el gobierno almorávide, y que un mejor entendimiento del cadiazgo de Alcira ha de tener en cuenta las características judiciales del levante en su conjunto.

\section{CADÍES DE ALCIRA}

En cuando a la composición del cadiazgo de Alcira las fuentes manejadas proporcionan los siguientes datos durante el periodo estudiado, es decir finales de la época de taifas y el periodo almorávide:

Periodo de taifas; durante este periodo aparecen dos cadíes:

*Abū Marwān 'Ubayd Allāh b. Aḥmad b. Maymūn al-Majzūmīi ${ }^{25}$. Lo único que sabemos sobre este personaje es que fue cadí de Alcira. Debió de morir en la segunda mitad del siglo V/XI.

*Abū Bakr Aḥmad b. Yahyyà b. Maymūn al-Majzūmīi ${ }^{26}$. Sabemos que fue cadí de Alcira en la época de taifas, y que al parecer familiar de anterior, probablemente eran padre e hijo. Murió en 461/1069. Está claro que el cadiazgo de la localidad, al menos a finales del periodo de taifas, fue acaparado por los miembros de la familia de los al-Majzūmī.

Periodo almorávide: en cuanto al periodo almorávide tenemos constancia de siete cadíes:

*Abū `Abd Allāh Muḥammad b. Wahb b. Muhammad b. Wahb b. Muḥammad b. Wahb, conocido por Nūh al-Gāfiqīi ${ }^{27}$. Natural de Zaragoza, ejerció allí como jurisconsulto. Luego lo nombró Abū l-Hasan b. Wāŷib cadí de Valencia y de Alcira, donde murió a finales de Şafar de 518/mediados de abril de 1124. Debió de haber

Azhār, ed. Rabat, 1978-1980, vol. III, 151. Véase también DE LA PUENTE, Cristina, "Vivre et mourir pour Dieu: ouvre et héritage d'Abū 'Alī al-Șadafî”, Studia Islamica, 88 (1998), 77-102.

${ }^{22}$ IBN AL-ABBĀR, al-Takmila, ed. El Cairo, no 368; IBN AL-ABBĀR, al-Mu ŷam, ed. F. CODERA, ${ }^{\circ} 41$; AL-DABB̄̄, Bugyat al-multamis, $\mathrm{n}^{\circ} 517$.

${ }^{23}$ IBN AL-ABBĀR, al-Takmila, ed. F. CODERA, no 1954; IBN AL-ZUBAYR, Şilat al-şila, vol. VII, n’ 319; IBN `ABD AL-MALIK, al-Ḍayl wa-l-takmila, ed. Iḥsān `ABBĀS, Beirut, 1965, vol. V/1, $\mathrm{n}^{\circ}$ 182; AL-ḌABB̄, Bugyat al-multamis, $\mathrm{n}^{\circ} 1274$.

${ }^{24}$ EL HOUR, Rachid, "El Levante de al-Ándalus en época almorávide: jueces y élites locales".

${ }^{25}$ IBN AL-ABBĀR, al-Takmila, ed. Al-Husaynī, El Cairo, 1955, p. 929.

${ }^{26}$ IBN AL-ABBĀR, al-Takmila, ed. Al-Husaynī, El Cairo, 1955, p. 44.

${ }^{27}$ IBN AL-ABBĀR, al-Takmila, ed. El Cairo, no 1191. 
sido cadí de un barrio o región en Valencia, ya que no es posible que fuera cadí de Valencia junto con Abū l-Hasan b. Wāŷib ${ }^{28}$. Disfrutaba de una posición prestigiosa en cuanto a su relación con el sultán, que le admitía en su palacio y en su intimidad.

*Abū Muhammad Ayyūb b. Muḥammad b. Wahb b. Muḥammad b. Wahb b. Muḥammad b. Wahb b. Ayyūb b. Wahb b. Bakr b. Sahl b. Ayyūb b. Ibrāhīm b. Nāŷiya b. Dāwūd b. Udad (Abad) b. Qawad b. 'Irmān b. Dāwūd b. Mu ād b. Nașr b. Yādir al-Gāfiqi $\overline{1}^{29}$. Sucedió a su padre Muhammad b. Wahb en el cadiazgo de Alcira y dirigió la oración en la mezquita aljama de Valencia por una corta temporada. Ibn Wahb había salido de Zaragoza cuando ésta cayó en manos de los cristianos. Llegó a Tortosa en la fiesta del sacrificio de 512/marzo 1119; después de una estancia allí de cinco meses, el 4 de Ramaḍān de 512/19 de diciembre de 1118, la ciudad fue tomada por los cristianos. Entonces se dirigió hacia Valencia, se movió por el Levante y finalmente se estableció en Granada desde el 14 de Rabī' II de 514/julio de 1120 hasta Rabī' I de 517/mayo de 1123, es decir aproximadamente 3 años. Volvió entonces a Valencia, en donde se casó. Murió el 3 ó 4 de Șafar de 576/29 o 30 de junio de 1180, a los 90 años. Fue enterrado, al día siguiente, dentro de una mezquita en Valencia ${ }^{30}$.

*Abū Bakr Aḥmad b. Ibrāhīm b. 'Īsà b. Maḥlū ${ }^{31}$. Fue nombrado cadí de Alcira por el cadí de Murcia, Abū Bakr b. Aswad al-Gassān̄īis tras su destitución se dedicó a la redacción de los documentos contractuales durante la época de la fitna.

*Abū Bakr `Atīq b. Asad b. `Abd al-Raḥmān b. Asad al-Anșārîỉ . Natural de Iniesta, creció en Murcia. Fue cadí de Denia y dos veces cadí de Játiva. En la primera ocasión lo nombró Abū Bakr b. Aswad y, en la segunda, Abū Zakariyyā' b. Gāniya después de haber sido designado para el cargo de la šūrà o consejo consultivo. Luego se le añadió el cadiazgo de Alcira.

${ }^{28}$ IBN AL-ABBĀR, al-Takmila, ed. El Cairo, no 1346; IBN `ABD AL-MALIK, al-Dayl wa-ltakmila, vol. VI, n 1047.

${ }^{29}$ IBN AL-ABBĀR, al-Takmila, ed. El Cairo, no 532.

${ }^{30}$ Los movimientos geográficos de este personaje son sólo uno de los ejemplos de la emigración de muchos alfaquíes y juristas que se vieron obligados a abandonar su tierra de origen e instalarse en otras zonas andalusíes, forzados a ello por las conquistas cristianas. Sobre este aspecto véase MARÍN, Manuela, "Des migrations forcées: les 'ulamā' d'al-Andalus face à la conquête chrétienne", en L'Occident Musulman et l'Occident Chrétien au Moyen Âge (Série: Colloque et Séminaires $n^{\circ} 48$ ), Rabat, 1995, 43-59.

${ }^{31}$ IBN AL-ABBĀR, al-Takmila, ed. El Cairo, no 170; IBN `ABD AL-MALIK, al-Dayl wa-ltakmila, ed. Muhammad BENŠARĪFA, Beirut (s.a.), vol. I, $\mathrm{n}^{\circ}$ 38. Véase también la entrada de ROSADO, María Dolores en Biblioteca de al-Andalus, de Ibn Aḍhà a Ibn Bušrà, vol. II (2009), pp. 354355 (n 309$)$.

${ }^{32}$ Véase la administración judicial de Murcia en EL HOUR, Rachid, La administración judicial almorávide en al-Andalus, capítulo VI.

${ }^{33}$ IBN AL-ABBĀR, al-Takmila, ed. Francisco CODERA, no 1933; IBN `ABD AL-MALIK, alDayl wa-l-takmila, ed. IḥSāN `ABBĀS, Beirut, 1965, vol. V/1, nº 230; IBN AL-ABBĀR, al-Mu ŷam, ed. Francisco CODERA, Madrid, 1885, nº 275. 
Estos datos confirman la dependencia judicial de Játiva respecto a Murcia, puesto que Abū Bakr b. Aswad era qā d̦i quḍāt al-Šarq (juez de los jueces del Levante). A esto se añade el hecho de que Abū Zakariyyā' Yahyà b. Gāniya, que era gobernador de Valencia y Murcia $^{34}$ en 528/1133-1134, nombró a `Atīq en la šūrà y luego cadí de Játiva y de Alcira. El mismo Abū Zakariyyā’ b. Gāniya nombró a Ibn `Āšir cadí de Murcia, de lo que parece deducirse una intervención directa -aunque no sistemática- por parte del poder político almorávide en los nombramientos de ciertas ciudades, aunque lo más llamativo es ver la máxima autoridad política y militar, es decir el gobernador de todo el Levante, interviniendo en el nombramiento del cadí de una localidad como Alcira. Eso confirma la gran la sensibilidad política y judicial del Levante, incluyendo claro está a Alcira.

Esta intervención, por otro lado, puede explicarse por el hecho de que los acontecimientos político-militares en al-Ándalus en esta época obligaron a los almorávides a introducir una serie de reformas administrativas, ante el miedo de perder el control sobre al-Ándalus y presionados por una serie de derrotas como la de la batalla de Cullera ${ }^{35}$ y después la de Albacar (al-Bakkār o al-Bakār) ${ }^{36}$; además la situación en Magreb tampoco ayudaba mucho, ya que los almorávides empezaron a perder mucho terreno ante los almohades.

En mi opinión, la situación conflictiva y crítica de Levante obligó al poder político a tomar precauciones de carácter jurídico, desarrollándose una política que iba a consistir en controlar directamente el poder judicial, interviniendo en los nombramientos, como demuestra el caso que se está analizando.

*Abū Marwān 'Ubayd Allāh b. Maymūn al-Anșāīī, Ibn al-Adīb ${ }^{37}$. Fue cadí de Alcira, murió en 556/1161-1162. Probablemente fue nombrado en la época almorávide, por la gran importancia que alcanzó esta localidad en dicho periodo.

*Abū `Amr y Abū Muhammad` Utiman b. Yūsuf b. Abī Bakr b. `Abd Barr b. Sayyidī b. Abī l-Qāsim b. Tabit b. `Abd Allāh b. Yahyyà b. Muḥammad b. `Abd al-

${ }^{34}$ Cf. IBN `ID̄ĀRĪ, al-Bayān al-mugrib, ed. Ihsān `ABBĀS, Beirut, 1967, vol. IV, p. 91. Cuando empezó la revuelta contra los almorávides, éste todavía era gobernador de Valencia; luego fue designado gobernador general de todo al-Ándalus. Cf. FIERRO, Maribel, "The $q \bar{a} \bar{d} \bar{\imath}$ as ruler" en Saber Religioso y poder político en el islam, madrid, 1994, 77-116, espe. 102; GUICHARD, Pierre, Les musulmans de Valence à la reconquête, Damasco, 1992, vol. I. 101.

${ }^{35}$ Cf. HUICI MIRANDA, Ambrosio, Historia musulmana de Valencia, vol. III, 65 y ss; MU'NIS, Ḥusayn,"Nuṣūs siyāsiyya", 97-140; véase también el trabajo de Investigación (inédito), Análisis histórico. En este trabajo hemos analizado la carta que envió el emir almorávide al ejército almorávide derrotado en Cullera. Dicha carta plasma dos hechos primordiales: la postura de los andalusíes hacia los almorávides y la incapacidad almorávide para defender al-Andalus.

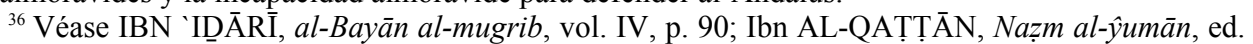
Mahmūd `Alī MAKKİ̃, Beirut, 1990, p. 215.

${ }^{37}$ IBN AL-ABBĀR, al-Takmila, ed. El Cairo, nº 2166. 
Barr b. Mu 'āfà al-Anșar ${ }^{-38}$. Natural de Zaragoza, fue cadí de Liria y de Alcira. Hizo la rihla en 531/1136-1137. Además realizó varios viajes por las coras de Valencia y se estableció en Liria. Murió en 577/1182.

El nombramiento de este cadí hace ver que el caso de Alcira fue un poco especial. Por un lado, se observa que Abū Bakr b. Maḥlūl fue nombrado cadí de Alcira por Abū Bakr b. Aswad al-Gassānī, que era cadí de Murcia. Por el otro, se ve que Abū `Abd Allāh b. Wahb b. Nūh al-Gāfiqī fue nombrado por el cadí de Valencia, Abū 1-Ḥasan b. Wâŷib, con lo cual la administración judicial de Alcira pasaba en este caso a depender de la de Valencia.

*Abū l-Hasan Țāhir b. Hayḍara b. Mufawwiz b. Aḥmad b. Mufawwiz b. Ahmad b. Mufawwiz b. `Abd Allāh b. Mufawwiz b. Gāfūl b. `Abd Rabbi-hi b. Șawāb b. Mudrik b. Salām b. Ŷa far al-Ma'āfirīīi . Natural de Játiva, fue nombrado cadí de Játiva y de Alcira al mismo tiempo, en 538/1143-1144, y ejerció este cargo durante casi 8 años, es decir, hasta 546/1151-1152. Presentó su dimisión, que le fue aceptada. Murió en Játiva en Muḥarram de 552/febrero de 1157.

No se sabe quién efectuó su nombramiento, pero por las razones citadas respecto al cadí anterior, lo más probable es que no fuera nombrado por el cadí de Murcia, sino por el gobernador almorávide. Ante los datos conservados sobre la administración judicial de Játiva, planteo por tanto la hipótesis de que en una primera etapa, desde la caída de la ciudad en manos de los almorávides hasta los años veinte del s. VI/XII, el cadí local dependiese del de Murcia, mientras que en una segunda etapa, el cadiazgo de Játiva pasó a depender directamente del gobernador almorávide. Otra posibilidad sería que este cadí fuera nombrado en el periodo almorávide y que conservara su cargo en época posterior, a pesar del cambio de gobierno. Me refiero al gobierno de Abū Muḥammad 'Iyạ̣ que se hizo con la zona del Levante tras la revuelta contra los almorávides.

Resulta también interesante que este cadí lo fuera al mismo tiempo de Játiva que hasta entonces había dependido de Murcia- y de Alcira, que dependía de Valencia. Quizá haya que ver en ello una muestra más de la intervención política en el mapa administrativo-judicial del Levante.

Creo que la política de nombramiento de los cadíes fue una herramienta muy importante que nos puede ayudar a entender el entramado judicial almorávide en alAndalus. En la época almorávide nos encontramos con algunos nombramientos de cadíes por otros, hecho que refleja claramente el papel de la jerarquía judicial en la organización de la administración de justicia. Las fuentes bio-bibliográficas nos hablan

${ }^{38}$ IBN `ABD AL-MALIK, al-Dayl wa-l-takmila, ed. vol. V/1, n 286; IBN AL-ABBĀR, alTakmila, ed. Francisco CODERA, no 1835; IBN AL-ZUBAYR, Șilat al-șila, ed. `Abd al-Salām HARRĀS y Sa'īd A`RĀB, al-Muhammadiyya, 1993, vol. VII, nº 136.

${ }^{39}$ IBN AL-ABBĀR, al-Takmila, ed. El Cairo, no 923; IBN `ABD AL-MALIK, al-Dayl wa-ltakmila, ed. Iḥsān `ABBĀS, Beirut, vol. IV, $\mathrm{n}^{\circ}$ 279. Véase también UZQUIZA BRTOLOMÉ, Aranzazu, LUCINI BAQUERIZO, María Mercedes, Las ciencias islámicas en Xàtiba, Valencia, 1991. 
del nombramiento de qāộ̀ l-ŷamāa de Córdoba al cadí de Almería, Abū `Abd Allāh Marwān b. `Abd al-Malik. Lo nombró Abū `Abd Allāh b. Hamdīn cadí de Almería y murió en 512/1118 ${ }^{40}$. Además sabemos que el cadí de Valencia efectuaba nombramientos de cadíes de su distrito. Por ejemplo, Abū 1-Hasan b. Wāŷib al-Qaysī nombró a Abū `Abd Allāh Muhammad b. Wahb b. Muhammad b. Wahb b. Muhammad b. Wahb, Nūḥ al-Gāfiqīi cadí de Valencia y de Alcira. El qāọ̄ qựāt al-Šarq Abū Bakr b. Aswad al-Gassānī nombraba a los cadíes de su distrito, entre otros casos registrados en la zona del Levante ${ }^{41}$.

Volviendo al cadiazgo de Alcira, vemos claramente que la evolución de la administración judicial de Alcira estuvo ligada a los cambios que sucedían en Valencia, al menos hasta la caída de la ciudad en manos del Cid. En segundo lugar, y basándonos en los datos que hemos destacado respecto a la historia de Alcira, pensamos que su administración judicial pasó por las siguientes etapas durante el período que nos ocupa:

a. La primera empezó con `Abd al- `Azīz b. `Amir y su hijo `Abd al-Malik, que, según la política aplicada por los reyes de taifas, en su mayoría, fueron quienes se encargaron del nombramiento de los cadíes de esta ciudad.

b. La segunda empezó con el gobernador de Valencia, nombrado por Yahyà b. Dī l-Nūn. A éste se le ofreció el derecho de nombrar a los cadíes de Valencia y sus dependencias. La misma política, según creemos, siguió en pie cuando este gobernador se independizó en Valencia.

c. La tercera empezó cuando se apoderó al-Qādir de la ciudad de Valencia. En este caso tenemos dos posibilidades:

* O bien ofreció el derecho de nombrar a los cadíes de las provincias al cadí de la ciudad, en este caso a Ibn Ŷaḥhāf, o bien se encargó personalmente de nombrar a los cadíes.

d. La cuarta empezó con los almorávides, pero esta vez, la administración judicial de Alcira funcionaba independientemente de la de Valencia, que estaba en manos del Cid.

Según los datos que ofrecen las fuentes bio-bibliográficas acerca de los nombramientos de los cadíes de Alcira en la época almorávide, podemos deducir lo siguiente:

Si los almorávides centraron la administración judicial del Levante en Murcia y Valencia tras la recuperación de esta última ciudad en 495/1102, la administración judicial de Alcira habría dependido de la de Valencia y de la de Murcia. Como testimonio de ello, vemos que, por una parte, Abū Bakr b. Maḥlūl fue nombrado cadí

\footnotetext{
${ }^{40}$ Véase EL HOUR, Rachid, La administración judicial, capítulo V.

${ }^{41}$ Véanse los detalles en el estudio de la justicia en el Levante en EL HOUR, Rachid, "El Levante de al-Andalus".
} 
de Alcira por Abū Bakr b. Aswad al-Gassānī que era cadí de Murcia, o mejor dicho qaḍ̄ quḍāt al-Šarq. Por otra parte, vemos que Abū `Abd Allāh b. Wahb b. Nūḥ alGāfiqī fue nombrado por el cadí de Valencia, Abū l-Ḥasan b. Wāŷib, con lo cual la administración judicial de Alcira pasaba en este caso a depender de la de Valencia.

No es posible que la misma administración dependiese de dos sedes centrales simultáneamente, por lo cual hemos de diferenciar entre dos etapas durante el período almorávide:

a. La primera puede situarse entre la caída de la ciudad en manos de los almorávides hasta los años veinte del siglo VI/XII, o al menos hasta la destitución de Abū 1-Ḥasan Wāŷib al-Qaysī en 518/1125.

b. La segunda abarca el periodo que se extiende desde 518/1125 hasta la decadencia del poder almorávide.

A estas observaciones se une otra más importante. Si comparamos la estructura social del cadiazgo de Alcira en las dos épocas, taifas y almorávide, deducimos lo siguiente:

Durante la época de taifas, el cadiazgo de Alcira estuvo dominado por la familia de los Banū Maymūn al-Majzūmī, procedentes de la misma ciudad, hasta el punto de que, según creemos, los dos cadíes eran parientes, o mejor dicho, el primero era padre del segundo, que le sucedió en el cadiazgo de Alcira por herencia ${ }^{42}$. Esta familia desaparece en la época almorávide, y aparece otra, la de los Banū Wahb alGāfiqī, que dominó el cadiazgo de la ciudad durante una buena parte de la presencia almorávide en la zona levantina. Hemos de tener muy en cuenta de que la nueva familia era de origen zaragozano, y probablemente sustituyera a la anterior, es decir la familia al-Majzūmī, en el cadiazgo de la ciudad. Este hecho era corriente en el periodo almorávide, ya que los nuevos dueños de al-Ándalus procuraron, entre otras cosas, apoyar la creación de nuevos poderes locales en varios lugares y localidad andalusíes, aunque el poder local de algunas ciudades de mucha importancia, como es Sevilla, Granada o Córdoba, hicieron frente a los planes de los almorávides, y consiguieron resistir y conservar su poder sobre el cadiazgo de sus respectivas ciudades, como la familia de los Banū Rušd, los Banū `Ațiyya, entre otros ${ }^{43}$, y de allí nacieron, entre otros, los pactos entre las familias andalusíes y el gobierno almorávide.

De todas formas, el cadiazgo de Alcira se vio afectado por el levantamiento general contra los almorávides, que tuvo lugar a partir de 539/1144-1145. Frente al silencio de las fuentes en cuanto a las características del cadiazgo de Alcira, no sabemos con exactitud de qué administración dependía. O bien de Murcia, cuyo cadí se proclamó independiente, o bien de Valencia, cuyo cadí, a su vez, se proclamó

\footnotetext{
${ }^{42}$ Sobre los cargos hereditarios véase especialmente el estudio de ÁVILA, María Luisa, "Cargos hereditarios en la administración judicial y religiosa de al-Andalus", en Saber religioso y poder político en el islam, Madrid: AECID, 1994, 27-37.

${ }^{43}$ Véanse el análisis de la administración de justicia de Córdoba, Sevilla, Granada, entre otras, en El Hour, Rachid, La administración judicial almorávide en al-Andalus.
} 
independiente, hasta que tomó el mando Abū Muḥammad b. 'Iyāḍ, que pudo unificar, de nuevo, el Levante ${ }^{44}$.

En cuanto a los demás cargos judiciales de Alcira, por ejemplo jurisconsultos, muftíes, șăhib al-ahkām, entre otros, las fuentes no proporcionan ningún dato, lo que puede llevarnos a deducir lo siguiente: bien que estos cargos realmente existieron y que las fuentes mantuvieron silencio al respecto, aunque esta posibilidad es poco probable, porque la localidad era importante y no tiene muchas lógica que las fuentes hayan informado sobre juristas y cadíes, y no hablaran de los juristas que pertenecieran al consejo consultivo de estos mismos cadíes. Esto nos lleva a plantear la siguiente posibilidad que reside en que los almorávides, y con ellos el poder local levantino se contentaron con el cargo de cadí y no vieron necesidad de crear más cargos judiciales en la localidad. El número de cadíes de Alcira, siete en época almorávide, puede considerarse una gran muestra de ello.

\section{CONCLUSIONES}

El cadiazgo de Alcira invita a hacer las siguientes reflexiones: durante todo el periodo estudiado la localidad levantina no dejó de gozar de cierta importancia, y se observa que ese interés incrementó de manera considerable en el periodo almorávide. Mi estudio de la administración de justicia en este periodo pone de manifiesto que la justicia era uno de los dominios que permitían medir el grado de importancia de cualquier ciudad o localidad. El cadiazgo de Alcira no deja de ser algo singular, sobre todo si lo comparamos con otras localidades, no sólo las consideradas periféricas sino con otras de gran importancia. El hecho de que fueran nombrados nueve cadíes en Alcira, 2 en época de taifas y 7 en época almorávide, no deja lugar a dudas de la situación singular, pero muy importante, que representó Alcira para los planes político-judiciales almorávides en al-Ándalus. No hemos de olvidar que en gran parte de las localidades periféricas propiamente dichas durante el mismo periodo el número de los jueces no superó la cifra de uno, en el mejor de los casos, porque los poderes político-judiciales se contentaron con nombrar un simple representante del cadí.

Los almorávides prestaron especial interés a la institución de la justicia andalusí, no sólo para impartir justicia, sino también para el ejercicio del mayor control posible sobre la población. Mi estudio de la distribución geográfica de las administraciones judiciales andalusíes en este periodo pone de relieve que una de las herramientas más eficaces a la que recurrieron los almorávides fue la proliferación tanto de las administraciones de justicia como de los cargos judiciales. El cadiazgo de Alcira es una buena muestra de la complejidad de la justicia en la zona del Levante en el periodo almorávide. Los almorávides prestaron especial interés a esta zona, entre otros, porque era zona fronteriza, y esta condición hizo que tuviera

${ }^{44}$ Véase EL HOUR, Rachid, La administración judicial almorávide en al-Andalus, capítulo VI. 
mecanismos propios de las sociedades de frontera y todo lo que conlleva de ventajas políticas y administrativas, pero sobre todo en lo que se refiere a una gestión "autonómica", reflejada especialmente en el dominio del poder local andalusí, el levantino en este caso, de la vida socio-religiosa de sus respectivas ciudades y localidades, siendo Alcira uno de los ejemplos.

Sobra decir que los acontecimientos políticos y militares influyeron en la evolución judicial de la localidad de Alcira. Se ha podido observar cómo Alcira experimentó cambios especiales, sobre todo si la comparamos con otras localidades periféricas levantinas. A lo largo del mismo periodo almorávide, apreciamos que el cadiazgo de Alcira dependió de las administraciones de justicia de Murcia y Valencia, capitales del Levante de la época; también observamos que el propio gobernador de todo el Levante interviene para nombrar algunos cadíes de Alcira. Son muestras que reflejan que Alcira y su cadiazgo realmente gozaron de una gran importancia, al margen de los cambios políticos y militares que sufrió la zona del Levante en su conjunto debido probablemente a los avances cristianos peninsulares.

El cadiazgo de Alcira, junto con el de las demás localidades levantinas, registra la existencia de redes familiares que dominaron el cadiazgo de la localidad, y parece que cobraron gran importancia con la llegada de los almorávides.

Y para cerrar estas reflexiones me inclino a pensar que Alcira experimentó un gran cambio administrativo en época almorávide, abandonando su condición de localidad rural para convertirse en una importante urbe con las condiciones propias de ciudades tan importantes como Valencia o Murcia, al menos desde el punto de vista de la organización de su justicia. 